\title{
Wat zijn de risico's van vroege sportspecialisatie op de gezondheid van kinderen?
}

B. Jidovtseff, $1 \square$

Email b.jidovtseff@ulg.ac.be

Email b.jidovtseff@uliege.be

1 Departement Bewegingswetenschappen, Onderzoekseenheid Jeugd, ULg, België

\section{Samenvatting}

Enkele wetenschappelijke studies uit de jaren 90 toonden aan dat wie in bepaalde domeinen zoals sport een zeer hoog niveau wil bereiken, al heel vroeg en intens moet beginnen te trainen. Wie te lang wacht, maakt maar weinig kans om ooit de top te bereiken. De media-aandacht voor jonge sporters, de organisatie van belangrijke jeugdcompetities en de prestatiedrang op erg jonge leeftijd, hebben bijgedragen tot vroege specialisaties. Echter toonden de onderzoekers aan dat die aanpak niet bijzonder efficiënt is en bovendien de ontwikkeling en de gezondheid van het kind in het gedrang kan brengen. De laatste jaren worden alternatieve en kindgerichte oplossingen voorgesteld als ontwikkelingsmodellen op lange termijn.

\section{Trefwoorden}

sportspecialisatie, AQ1

Dit artikel is een vertaling van het artikel uit: Percentiel 2016;21:6-10.

\section{Inleiding}

Sport neemt in onze moderne samenleving een belangrijke plaats in. Daardoor is 
er een soort cultus van de sportprestatie ontstaan. De olympische uitdagingen (sportieve, economische, mediatieke en politieke) zijn zo groot geworden dat de jacht op medailles belangrijker is geworden dan het credo 'deelnemen is belangrijker dan winnen'. Niet alleen volwassenen willen tot elke prijs zo goed mogelijk presteren, ook kinderen, en wel al op steeds jongere leeftijd. De praktijkmodellen zijn veranderd en zetten kinderen ertoe aan om zich al heel vroeg te specialiseren. Een dergelijke elitaire benadering houdt echter heel wat risico's in voor de ontwikkeling en de gezondheid van het kind.

\section{Vroege specialisatie}

Het concept van de vroege specialisatie maakte in de jaren negentig opgang na de publicatie van de werken van Ericsson en medewerkers [1]. Zij toonden aan dat intens en vroeg trainen in een bepaald domein van wezenlijk belang is om expertise te ontwikkelen. Wat een kind niet leert op heel jonge leeftijd, kan het later niet meer inhalen, zo stelden de auteurs. In uiteenlopende disciplines zoals muziek, schaken, zwemmen of tennis zouden kinderen ongeveer 10.000 uur of 10 jaar intens moeten trainen om later een topniveau te bereiken. Meer was niet nodig om trainers en ouders ervan te overtuigen dat hun kind alleen een groot kampioen kan worden als het zich al heel vroeg toespitst op een bepaalde sport, ten koste van heel wat andere activiteiten [2]. Het parcours van enkele notoire kampioenen die zich al op heel jonge leeftijd specialiseerden (bijvoorbeeld Tiger Woods, Amanda Beard, Serena Williams) voedde het idee dat om een groot kampioen te worden, men al op heel jonge leeftijd moet schitteren. Modellen en doelstellingen die eigenlijk voor volwassenen zijn bedoeld, worden ook toegepast op kinderen: intensief en doelgericht trainen, hyperspecifieke motorische ontwikkeling, resultaten neerzetten, alleen de besten selecteren en geen tijd steken in de zwaksten. Sommige ouders, die toch alleen maar het beste willen voor hun kind, durven zich wel eens te verliezen in dit competitieve systeem. De vrees om de trein naar het succes te missen of voorbij te gaan aan die ene zeldzame parel, heerst alomtegenwoordig bij ouders, trainers en sportdirecteurs.

Door volledig op te gaan in de strijd voor het succes van hun kind of om zich een goede ouder te tonen ten opzichte van anderen, wakkeren sommige ouders het concept van een vroege specialisatie in de sport nog aan. Hoewel de kans dat het kind een grote sportcarrière tegemoet gaat niet groter is dan de kans om ooit de 
lotto te winnen, zijn sommigen bereid om er alles voor op te geven. Ook de cultus van de sportidolen doet heel wat kinderen dromen om ooit een Lionel Messi of een Usain Bolt te worden. Deze factoren dragen bij tot een immense sociale druk (van de sportfederaties, de ouders, de trainers en de kinderen zelf) om zich al heel vroeg te specialiseren in een sport [3]. Echter houdt het model op lange termijn geen stand. Enkele getalenteerde jongeren konden hun droom waarmaken en werden grote kampioenen, maar de meesten vielen - anoniem van hun voetstuk, met soms dramatische gevolgen. Studies bij topatleten toonden aan dat een vroege specialisatie in de sport niet van wezenlijk belang is en dat heel wat topatleten in hun jeugd verschillende sporten hebben beoefend voordat ze zich specialiseerden $[4,5,6]$.

Vroeg trainen in een specifieke discipline kan wel de prestaties verbeteren op korte termijn, maar zegt niets over een eventueel succes op volwassen leeftijd en biedt daarvoor geen enkele garantie [2]. Talentscouting bij heel jonge kinderen, zoals we die zien in landen als Duitsland, de voormalige USSR en de VS, werpt slechts weinig vruchten af: minder dan $2 \%$ van de geselecteerden bereikt ooit de internationale top [2]. Toch wordt vandaag nog heel veel ingezet op talenten van zeer jonge leeftijd.

Het groeiproces van kinderen is een variabele die de resultaten bij de jongeren enorm beïnvloedt, de kaarten door elkaar schudt en uiteindelijk tot het inzicht leidt dat men zich vergist heeft. Vroegrijpe kinderen zijn bevoordeeld in sporten waarin de fysieke component (lengte, kracht) een rol speelt, terwijl kleine en lichte kinderen het voordeel genieten in turnsporten met rotaties. In selectiesystemen die enkel zijn gebaseerd op prestatiecriteria, krijgen kinderen met een gunstige maturiteit alle kansen en blijven de anderen veelal in de kou staan.

\section{Voor elke sport een eigen aanpak}

Wetenschappers zijn het erover eens dat specialisatie onmisbaar is voor wie ooit een hoog niveau wil bereiken [1, 2, 3, 4]. Maar op welke leeftijd zou een kind zich moeten specialiseren en wat zijn de gevolgen daarvan op de ontwikkeling? Om die vraag te beantwoorden, moeten we verschillende sportcategorieën van elkaar onderscheiden: sporten met een snelle specialisatie en sporten met een geleidelijke specialisatie (tab. 1). De sporten met een snelle specialisatie 
omvatten hoofdzakelijk artistieke en acrobatische disciplines zoals turnen, dansen of kunstschaatsen. Ze verschillen van de andere sporten omdat de kinderen heel complexe vaardigheden moeten leren voordat ze de maturiteit bereiken [7]. Een studie toont aan dat wie een hoog niveau wil bereiken in het turnen, zich al vroeg moet beginnen te specialiseren: de eerste stappen moeten worden gezet tussen 4 en 8 jaar. Het trainen wordt ieder jaar intenser en vanaf 11-12 jaar offeren de topturners er al hun vrije tijd voor op [8]. Andere sporten met een geleidelijke specialisatie zouden pas specialisatie vergen vanaf de leeftijd van 12 jaar [7]. Alle sporten met een hoofdzakelijk fysieke component (atletiek, wielrennen, roeien, gewichtheffen, triatlon, enzovoort) kunnen na de puberteit worden aangevat [9]. Sporten met een technisch-tactische component (voetbal, tennis, basketbal, enzovoort) daarentegen worden bij voorkeur al vroeg ontdekt, zonder dat een vroege specialisatie echt nodig is. Voor deze sporten spreken de wetenschappelijke studies elkaar tegen: sommige beweren dat vroege diversificatie haar vruchten afwerpt [5], andere benadrukken eerder het tegendeel [10]. Bijkomend onderzoek lijkt noodzakelijk, maar alle resultaten bevestigen dat het belangrijk is om al vroeg, georganiseerd of niet, met een sport te beginnen.

\section{Tabel 1}

Op welke leeftijd moeten kinderen zich beginnen te specialiseren? De aanpak verschilt naar gelang de sport

AQ2

\begin{tabular}{|c|c|c|c|}
\hline & \multirow[t]{2}{*}{$\begin{array}{l}\text { sporten met een } \\
\text { snelle specialisatie }\end{array}$} & \multicolumn{2}{|c|}{ sporten met een geleidelijke specialisatie } \\
\hline & & $\begin{array}{c}\text { belangrijke } \\
\text { technisch-tactische } \\
\text { component }\end{array}$ & $\begin{array}{c}\text { belangrijke fysieke } \\
\text { component }\end{array}$ \\
\hline voorbeelden & $\begin{array}{l}\text { turnen, dansen, } \\
\text { kunstschaatsen ... }\end{array}$ & $\begin{array}{l}\text { voetbal, tennis, } \\
\text { basketbal, hockey, } \\
\text { badminton, judo }\end{array}$ & $\begin{array}{l}\text { atletiek, } \\
\text { gewichtheffen, } \\
\text { roeien, triatlon ... }\end{array}$ \\
\hline \multirow[b]{2}{*}{$\begin{array}{l}\text { wanneer } \\
\text { beginnen? }\end{array}$} & $\begin{array}{l}\text { vroeg beginnen } \\
\text { (tussen } 5 \text { en } 8 \text { jaar) }\end{array}$ & vroeg diversifiëren & vroeg diversifiëren \\
\hline & $\begin{array}{l}\text { aanmoedigen tot het } \\
\text { beoefenen van } \\
\text { complementaire } \\
\text { sporten }\end{array}$ & $\begin{array}{l}\text { beginnen tussen } 5 \text { en } \\
10 \text { jaar }\end{array}$ & $\begin{array}{l}\text { de sport kan worden } \\
\text { ontdekt na } 12 \text { jaar }\end{array}$ \\
\hline aanbevelingen & $\begin{array}{l}\text { belang hechten aan } \\
\text { het plezier van het }\end{array}$ & $\begin{array}{l}\text { belang hechten aan } \\
\text { het plezier van het }\end{array}$ & $\begin{array}{l}\text { belang hechten aan } \\
\text { het plezier van het }\end{array}$ \\
\hline
\end{tabular}




\section{sporten met een snelle specialisatie \\ sporten met een geleidelijke specialisatie}

\begin{tabular}{|c|c|c|}
\hline & $\begin{array}{c}\text { belangrijke } \\
\text { technisch-tactische } \\
\text { component }\end{array}$ & $\begin{array}{l}\text { belangrijke fysieke } \\
\text { component }\end{array}$ \\
\hline sporten & $\begin{array}{l}\text { sporten. Periodes van } \\
\text { vrij en spontaan } \\
\text { sporten bevorderen }\end{array}$ & sporten \\
\hline $\begin{array}{l}\text { de trainingen en } \\
\text { oefeningen } \\
\text { aanpassen aan } \\
\text { kinderen }\end{array}$ & $\begin{array}{l}\text { in de eerste plaats de } \\
\text { globale motoriek } \\
\text { ontwikkelen }\end{array}$ & $\begin{array}{l}\text { periodes van vrij en } \\
\text { spontaan sporten } \\
\text { bevorderen }\end{array}$ \\
\hline $\begin{array}{l}\text { toezien op een } \\
\text { gezonde voeding }\end{array}$ & $\begin{array}{l}\text { kinderen ertoe } \\
\text { aanzetten om } \\
\text { meerdere sporten te } \\
\text { beoefenen }\end{array}$ & $\begin{array}{l}\text { kinderen ertoe } \\
\text { aanzetten om } \\
\text { meerdere sporten te } \\
\text { beoefenen }\end{array}$ \\
\hline $\begin{array}{l}\text { traumatiserende } \\
\text { praktijken vermijden }\end{array}$ & $\begin{array}{l}\text { niet te vroeg } \\
\text { specialiseren in } \\
\text { slechts een aspect van } \\
\text { de sport }\end{array}$ & $\begin{array}{l}\text { in de eerste plaats de } \\
\text { globale motoriek } \\
\text { ontwikkelen }\end{array}$ \\
\hline $\begin{array}{l}\text { de kinderen tijd } \\
\text { gunnen voor andere } \\
\text { activiteiten }\end{array}$ & $\begin{array}{l}\text { aangepaste en } \\
\text { originele } \\
\text { competitiemodellen }\end{array}$ & $\begin{array}{l}\text { aangepaste en } \\
\text { originele } \\
\text { competitiemodellen }\end{array}$ \\
\hline $\begin{array}{l}\text { aangepaste en } \\
\text { originele } \\
\text { competitiemodellen }\end{array}$ & \multirow{2}{*}{$\begin{array}{l}\text { de selecties van de } \\
\text { jongeren niet enkel } \\
\text { baseren op prestaties }\end{array}$} & \multirow{2}{*}{$\begin{array}{l}\text { de selecties van de } \\
\text { jongeren niet enkel } \\
\text { baseren op prestaties }\end{array}$} \\
\hline $\begin{array}{l}\text { de selecties van de } \\
\text { jongeren niet enkel } \\
\text { baseren op prestaties }\end{array}$ & & \\
\hline
\end{tabular}

\section{Risico's voor de ontwikkeling en de gezondheid}

Het feit dat jongeren zich al vroeg specialiseren in een sport en daar goede prestaties in behalen, is dus niet voorspellend voor succes op volwassen leeftijd. Maar wat is de impact van die aanpak op de ontwikkeling en de gezondheid van het kind?

Een van de risico's van een vroege specialisatie is dat het kind een te specifieke motoriek ontwikkelt, waardoor het later op een competentiebarrière zal stuiten en het moeilijker zal krijgen om een hoger niveau te bereiken [11]. Om de complexe 
en specifieke vaardigheden van een sport te kunnen aanleren, heeft het kind een brede motorische basis nodig; die zal het vermogen om motorische vaardigheden te verwerven op lange termijn alleen maar bevorderen. Vooral tussen de leeftijd van 3 en 8 jaar moeten deze motorische basisvaardigheden worden ontwikkeld $[7,11]$. Het risico van een vroege specialisatie is dat in deze kritieke periode te specifieke motorische vaardigheden moeten worden aangeleerd waardoor het kind het in zijn latere leven moeilijk zal krijgen om andere sporten te ontdekken [12].

In de meeste sporten worden de motorische vaardigheden geleidelijk aan aangeleerd. Dat leerproces eindigt in de tweede fase van de puberteit, een periode die uitermate geschikt is om de techniek te perfectioneren. In sportdisciplines zoals kunstschaatsen, turnen of dansen daarentegen, moeten de complexe bewegingen om biomechanische redenen al op heel jonge leeftijd worden aangeleerd. De lichaamsbouw van kinderen (klein en licht) vergemakkelijkt de acrobatische bewegingen. Momenten van inertie zijn beperkt en de rotaties worden bevorderd [13]. Vooral in de puberteit van meisjes is het een hele uitdaging om een biomechanisch gunstige lichaamsbouw te behouden. Om hun niveau te behouden volgen sommige jonge sportsters soms drastische diëten die schadelijke gevolgen kunnen hebben voor hun prestaties en gezondheid. Een onaangepaste voeding gecombineerd met overtraining, zou een negatieve energiebalans bevorderen en een verhoogde catecholaminerge respons, en zo de endocriene functie aantasten $[14,15]$. Heel wat topturnsters kampen bijvoorbeeld met amenorroe en een vertraagde en laattijdige groei [15]. Over het verband tussen intensief sporten en groei, vooral bij vrouwelijke turnsters, zijn al heel wat debatten gevoerd onder wetenschappers $[15,16]$.

Een van de grootste problemen van een vroege specialisatie, is het hogere blessurerisico als gevolg van het intensief herhalen van specifieke bewegingen. Die kunnen het voortbewegingsapparaat overbelasten (peesontstekingen, apofysosen, vermoeidheidsfracturen, enzovoort) en een onevenwicht creëren [14]. Om de risico's te beperken raden experts aan om niet meer dan 5 keer per week dezelfde sport te beoefenen en ieder jaar een pauze van 2 tot 3 maanden in te lassen; om de bewegingen te diversifiëren en toe te zien op een goed evenwicht van het hele lichaam $[14,17,18]$. Het is bijvoorbeeld interessant om bilateraal te werken aan de motoriek, maar ook om, wat de spiergroepen betreft, de agonisten en antagonisten te belasten. Een interessante vaststelling is dat het 
beoefenen van verschillende sporten het blessurerisico zou verminderen [17]. Wetenschappers onderzochten ook de psychologische impact van de vroege specialisatie. Sociale druk en prestatiedrang verhogen de stress, werken angst in de hand en kunnen leiden tot psychologische uitputting of vroegtijdige opgave van de activiteit $[3,12]$. Ook sociaal isolement of interferenties met de normale ontwikkeling van het kind worden vaak vastgesteld [3, 12]. Omdat het kind zich in bepaalde sporten $100 \%$ moet inzetten, kan het ook geen normale jeugd beleven. De praktijk die Ericsson [1] aanbeveelt om de ontwikkeling te optimaliseren, kan op zich ook niet bijzonder prettig zijn. Dat is een probleem, want plezier is een fundamenteel element in de ontwikkeling van de intrinsieke motivatie en de liefde voor de sport op lange termijn [6, 7].

\section{Welk alternatief?}

Behalve in enkele sporten met een snelle specialisatie, lijkt het verstandiger om kinderen aan te sporen om meerdere sporten te beoefenen en zich pas vanaf hun puberteit geleidelijk aan te laten specialiseren in een discipline. Sportieve ontwikkelingsmodellen op lange termijn, zoals het Développement à long terme de l'athlète (DLTA) [7] of het Developmental Model of Sport Participation (DMSP) [19], bevelen deze vroege diversificatie aan. Ze geeft immers niet alleen uitzicht op een langere topsportcarrière, maar stelt de deelnemers ook in de gelegenheid om verschillende sporten te ontdekken. Bovendien verlaagt deze aanpak het blessurerisico en draagt ze bij tot de ontwikkeling van een brede motorische basis, wat de leer- en aanpassingscapaciteiten van de sporters alleen maar verhoogt.

Gediversifieerd sporten lijkt voordelen te bieden: vaardigheden die in de ene sport worden aangeleerd, kunnen immers ook van pas komen in een andere sport [20]. Balhantering en trajectperceptie bijvoorbeeld zijn fundamentele vaardigheden die van nut zijn in zowel basketbal, handbal als volleybal. En de fysieke vaardigheden die worden opgedaan in het voetbal, zijn ook nuttig in andere teamsporten. Verplaatsingen naar de partners en tegenstanders, beantwoorden in heel wat groepssporten aan dezelfde logica. Uiteraard is de overdracht van vaardigheden des te efficiënter als de sporten tot hetzelfde domein behoren $[4,20]$. De complementariteit van bepaalde sporten biedt nieuwe mogelijkheden. Heel wat polsstokspringers zijn voormalige turners die met succes zijn overgeschakeld op een andere sport. 
Sportbeoefening is hoe langer hoe meer gestructureerd en omkaderd, wat de mogelijkheden van vrij en spontaan sporten vermindert. Toch blijkt uit retrospectieve studies dat heel wat topsporters in hun jeugd urenlang spontaan hebben kunnen sporten. Vrij sporten zou de creativiteit en het aanpassingsvermogen in de sport verbeteren [19] en dus meer moeten worden aangemoedigd.

Bij jeugdsporten is het ook belangrijk dat de kinderen er plezier aan beleven. Dat verbetert immers de intrinsieke motivatie en voorkomt dat het kind zijn sport snel beu wordt. Plezier zou een pedagogische uitdaging moeten zijn voor alle jeugdtrainers.

Bij sporten met een snelle specialisatie moeten de kinderen al vroeg bepaalde technische vaardigheden aanleren, maar trainers en ouders moeten toezien op de goede ontwikkeling van alle kinderen, met aandacht voor hun gezondheid op lange termijn. Het beoefenen van een andere, complementaire sport moet worden aangemoedigd. Turnen bijvoorbeeld gaat perfect samen met dansen. Ook het ludieke aspect van de sport is voor kinderen belangrijk. De trainingen van kinderen en adolescenten moeten worden aangepast om endocriene stoornissen te verminderen, blessures te vermijden en de kinderen toch een minimum aan vrije tijd te gunnen.

Competitiemodellen voor kinderen zijn vaak miniatuurversies van de competitiemodellen voor volwassenen, en dat is een probleem. Omdat het accent veelal op winnen en prestaties ligt, zullen trainers eerder mikken op resultaten op korte termijn dan op geleidelijk aan leren. Die prestatiedrang legt heel wat gewicht op de schouders van de kinderen en bepaalt de inhoud van hun trainingen: de nadruk ligt niet op de prestaties op lange termijn, maar op de prestaties van het komende weekend. Alleen de besten van het moment worden geselecteerd, de anderen blijven op de bank zitten. Omdat zoveel belang wordt gehecht aan competities, kan het kind bijna niet anders dan slechts een sport beoefenen. In sommige clubs moeten kinderen die niet alle trainingen bijwonen, tijdens wedstrijden op de bank blijven zitten. Er zijn zelfs clubs die de kinderen verbieden om nog aan andere sporten te doen. Experts zijn het erover eens dat er te veel belang wordt gehecht aan jeugdcompetities en dat die zelden zijn aangepast aan de behoeften van kinderen [7, 19]. De nadruk zou moeten liggen op leren en deelnemen, en niet zozeer op prestatie. Er zouden andere 
voorwaarden moeten worden opgelegd (regels, duur, materiaal, aantal kinderen, beperkt aantal verplaatsingen) om de inspanningen aan te passen en de integratie te bevorderen van alle kinderen. Helaas kennen innoverende modellen zoals het concept Kids' Athletics in de atletiek, of de lokale minitoernooien in collectieve sporten, slechts een bescheiden succes. Andere initiatieven zouden zich kunnen inspireren op de aanbevelingen om meerdere sporten te beoefenen om de kinderen multisportcompetities aan te bieden. Bij volwassenen zien we hoe participatieve activiteiten zoals joggen, trails of fitness steeds populairder worden. Op dezelfde manier zouden heel wat kinderen plezier kunnen beleven aan ludieke sportactiviteiten waarbij ze hun vaardigheden kunnen aanwenden zonder per se prestaties te moeten neerzetten. Nieuwe competitievormen, gebaseerd op de reële behoeften van de kinderen in plaats van op de competitiemodellen voor volwassenen, kunnen de jeugd ertoe aanzetten om gediversifieerder, ludieker en minder prestatiegericht te sporten, geheel volgens de aanbevelingen van de wetenschappelijke experts.

\section{Conclusie}

De voordelen van een vroege specialisatie in de sport wegen nauwelijks op tegen de risico's die ze inhoudt. In gelijk welke sport zouden in de eerste plaats de ontwikkeling en de goede gezondheid van het kind centraal moeten staan. De aanpak kan variëren naargelang de sport (tab. 1) maar hoe dan ook wordt aanbevolen om te zorgen voor een brede motorische basis, de kinderen aanvankelijk verschillende sporten te laten beoefenen, aandacht te besteden aan het plezier van het sporten, de kinderen voldoende ruimte te gunnen om vrij te sporten en de trainingen aan te passen aan het feit dat het om kinderen gaat. Daarnaast zou ook het belang van de competities moeten worden gerelativeerd en zouden de aangeboden modellen meer moeten tegemoetkomen aan de noden van de kinderen.

\section{Figuur 1}

AQ3

AQ4 


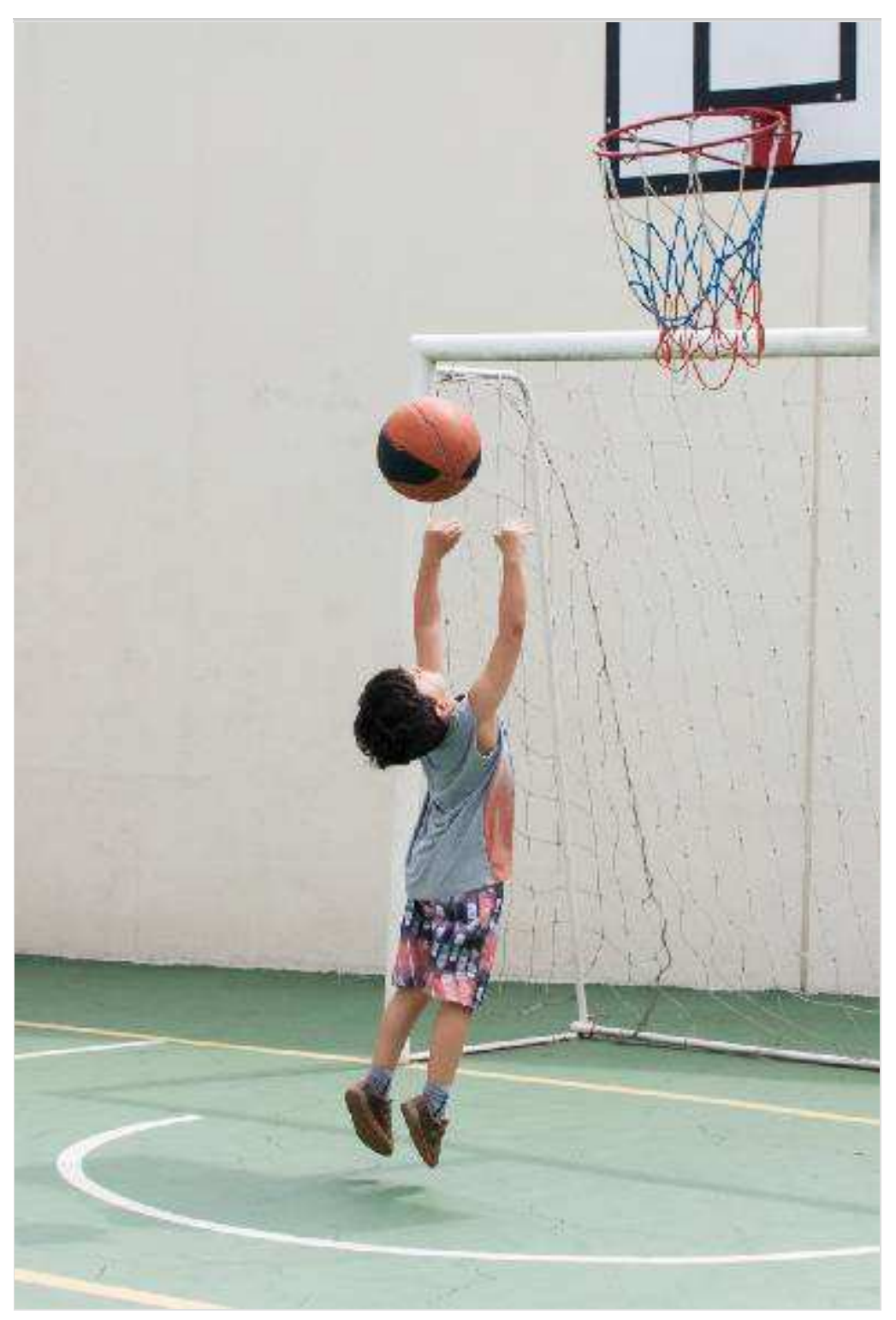

\section{Literatuur}

1. Ericsson KA, Krampe RT, Tesch-Römer C. The role of deliberate practice in the acquisition of expert performance. Psychol Rev. 1993;100:363-406.

2. Malina RM. Early sport specialization: roots, effectiveness, risks. Curr Sports Med Rep. 2010;9:364-71.

3. Gould D. Early sport specialization: a psychological perspective. J Phys Health Educ Recreat Dance. 2010;81:33-7.

4. Baker J. Early specialization in youth sport: a requirement for adult 
expertise? High Abil Stud. 2003;14:85-94.

5. Baker J, Cote J, Abernethy B. Sport-specific practice and the development of expert decision-making in team ball sports. J Appl Sport Psychol. 2003;15:12-25.

6. Côté J, Lidor R, Hackfort D. Issp position stand: To sample or to specialize? Seven postulates about youth sport activities that lead to continued participation and elite performance. Int J Sport Exerc Psychol. 2009;7:7-17.

7. Balyi I, Way R, Higgs C. Long-term athlete development. : Human Kinetics; 2013.

AQ5

8. Law MP, Côté J, Ericsson KA. Characteristics of expert development in rhythmic gymnastics: a retrospective study. Int J Sport Exerc Psychol. 2007;5:82-103.

9. Moesch K, Elbe AM, Hauge ML, Wikman JM. Late specialization: the key to success in centimeters, grams, or seconds sports. Scand J Med Sci Sports. 2011;21:e282-e90.

10. Ford PR, Ward P, Hodges NJ, Williams AM. The role of deliberate practice and play in career progression in sport: the early engagement hypothesis. High Abil Stud. 2009;20:65-75.

11. Wiersma LD. Risks and benefits of youth sport specialization: perspectives and recommendations. Pediatr Exerc Sci. 2000;12:13-22.

12. Branta CF. Sport specialization: developmental and learning issues. J Phys Educ Recreat Dance. 2010;81:19-28.

13. Mattson JM, Richards J. Early specialization in youth sport: a biomechanical perspective. J Phys Educ Recreat Dance. 2010;81:26-8.

14. Kaleth AS, Mikesky AE. Impact of early sport specialization: a physiological perspective. J Phys Educ Recreat Dance. 2010;81:29-37. 
15. Caine D, Bass S, Daly R. Does elite competition inhibit growth and delay maturation in some gymnasts? Quite possibly. Pediatr Exerc Sci. $2003 ; 15: 360-72$.

16. Baxter-Jones AD, Maffulli N, Mirwald RL. Does elite competition inhibit growth and delay maturation in some gymnasts? Probably not. Pediatr Exerc Sci. 2003;15:373-82.

17. American Academy of Pediatrics. Intensive training and sports specialization in young athletes. Pediatrics. 2000;106:154-7.

18. Brenner JS. Overuse injuries, overtraining, and burnout in child and adolescent athletes. Pediatrics. 2007;119:1242-5.

19. Côté J, Vierimaa M. The developmental model of sport participation: 15 years after its first conceptualization. Sci Sports. 2014;29:S63-S9.

20. Schmidt RA, Wrisberg CA. Motor learning and performance, a problembased learning approach. Champaign: Human Kinetics; 2000. 